\title{
Soil and Rhizosphere Bacterial Diversity in Maize Agro- Ecosystem
}

\author{
María T. Federici ${ }^{1}$, Natalia Bajsa ${ }^{2}$, Paula Lagurara ${ }^{2}$, Santiago Revale ${ }^{3}$, Jackson A. Marcondes ${ }^{4} \&$ Marco Dalla \\ Rizza $^{1}$ \\ ${ }^{1}$ Unidad de Biotecnología. Estación Experimental Wilson Ferreira Aldunate- INIA Las Brujas- Instituto \\ Nacional de Investigación Agropecuaria. Rincón del Colorado, Canelones, Uruguay \\ ${ }^{2}$ Laboratorio de Ecología Microbiana. Departamento de Bioquímica y Genómica Microbianas, Instituto de \\ Investigaciones Biológicas Clemente Estable, Montevideo, Uruguay \\ ${ }^{3}$ Instituto de Agrobiotecnología Rosario (INDEAR). Plataforma de Genómica y Bioinformática. Rosario, Santa \\ $\mathrm{Fe}$, Argentina \\ ${ }^{4}$ Laboratório de Genética Aplicada. Departamento de Biologia Aplicada à Agropecuária. Universidad Estadual \\ Paulista, Jaboticabal, São Paulo, Brazil \\ Correspondence: María T. Federici. Unidad de Biotecnología. Estación Experimental INIA Las Brujas Km 10 \\ Ruta 48, Rincón del Colorado, Canelones, Uruguay. Tel: 0598-2367-7641. E- mail: mfederici@ inia.org.uy
}

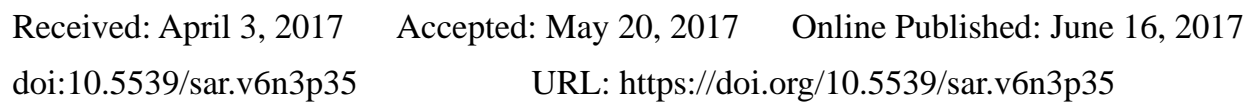

\begin{abstract}
Management practices used in maize production have an impact on soil agro- ecosystems where different microbial communities coexist. Soil inhabiting bacteria are numerous and diverse, but we know very little about their ecological distribution. Here we analyzed the bacterial community diversity in the rhizosphere of two transgenic maize cultivars, in agricultural soil before sowing and in non-cultivated soil in an experimental site in the south region of Uruguay. We followed two culture-independent methods: DGGE (denaturing gradient gel electrophoresis) and 454-pyrosequencing of 16S rRNA gene amplicon. Through pyrosequencing, the three environments analyzed presented differences in terms of bacterial composition. However, no differences were found in the relative abundance of the ten most represented phyla in the rhizosphere of the two cultivars at different phenological stages. We found significant differences of Bacteroidetes, Gemmatimonadetes, Planctomycetes, Proteobacteria and Verrucomicrobia phyla when comparing agricultural and non-cultivated soils, as well as a significant enrichment of members of the phylum Gemmatimonadetes in all rhizosphere samples compared to soil. Through DGGE analysis we evidenced that maize rhizosphere bacterial communities changed at different phenological stages in both cultivars. We also provided baseline information about bacterial specific taxa within maize agro- ecosystem for further evaluation of possible rhizosphere bacterial community shifts of genetically modified maize cultivars under different management practices.
\end{abstract}

Keywords: metagenomics, transgenic maize, pyrosequencing, DGGE, rhizosphere, soil bacteria

\section{Introduction}

The rhizosphere, the narrow zone of soil that is influenced by root secretions, can contain up to $10^{11}$ microbial cells per gram of root (Egamberdieva et al. 2008) and more than 30,000 prokaryotic species (Mendes et al. 2011). The collective genome of this microbial community is much larger than that of the plant and is also referred to as the plant's second genome. Recent advances in plant-microbe interactions research revealed that plants are able to shape their rhizosphere microbiome as evidenced by the fact that different plant species host specific microbial communities when grown on the same soil (Brendensen et al., 2012). The easily available carbon sources exert a great selective pressure on the enrichment of soil bacteria and may attract both beneficial and detrimental bacteria (Dohrmann et al. 2012). Rhizosphere microorganisms in turn exert strong effects on plant growth and development by nutrient solubilization, $\mathrm{N}_{2}$ fixation or by the production of plant hormones (Höflich et al., 1994; van Loon et al., 1998; Gomes et al. 2001).

Genetically modified cultivars might affect the structural and functional diversity of rhizosphere microbial communities, e.g. by an altered root morphology and physiology, plant exudation (Engelhard et al. 2000), thus altering the balance of plant-beneficial and deleterious microbes. Among the reasons to explain the increased 
adoption of genetically-engineered Bt maize crops in the world is a significant reduction in the use of synthetic insecticides in fields, simplicity in the management of insect pests, and clear advantages for the environment, growers and consumers (Blanco et al., 2016). However, potential effects of a new GM crop on the bacterial community structure and function need to be assessed in the context of natural variability, e.g. seasonal shifts (Gomes et al. 2001).

One of the major potential environmental risks associated with the use of transgenic Bt-maize varieties expressing insecticidal proteins from Bacillus thuringensis is their effect on soil and its inhabiting non-target organisms, including bacteria, as Bt protein is released through the roots (Saxena et al. 2001). Although it is believed that Bt proteins of these plants have a very narrow spectrum of activity, making them nearly pest-specific, some studies question this statement (Castaldini et al., 2005; Hannula et al., 2014).

Most studies on rhizosphere and soil bacteria community structure have been performed using culture-dependent approaches. However, a high percentage of naturally occurring bacteria still cannot be cultured using classic bacterial culture techniques. Microbial community analysis assessing biodiversity variability with classical fingerprinting techniques, such as DGGE (denaturing gradient gel electrophoresis), lacks information about microbial taxonomic identity and only captures the most dominant species in the environment. Nowadays, $16 \mathrm{~S}$ rRNA gene amplicon pyrosequencing has been largely implemented to determine microbial diversity and community structure in many different ecosystems, allowing a more exhaustive characterization of community patterns and composition (Carbonetto et al. 2014). Using both 16S rRNA gene DGGE and

454- pyrosequencing technology, we aim to analyze possible changes in composition and diversity of bacterial populations in: i) rhizosphere during maize growth cycle at elongation, flowering and maturity of two transgenic maize cultivars: 699 MGRR and DK feed2 RR (MONSANTO-DEKALB); and in ii) agricultural soil before sowing and non-cultivated soil near the experimental site. We will also discuss survival strategies of the predominant bacterial taxa within the studied environments, providing a baseline information about bacterial diversity within the maize agro- ecosystem in an experimental site at INIA Las Brujas (National Institute of Agriculture Research), in the south region of Uruguay.

\section{Method}

\subsection{Site Description and Maize Cultivars}

Soil samples were taken from an experimental field between January and May 2012 at INIA (National Institute of Agricultural Research) which is located at Rincón del Colorado, Canelones, Uruguay. The whole country has the following climatic characteristics: temperate, moderate and rainy climate (temperature of the coldest month between $-3^{\circ}$ and $18^{\circ} \mathrm{C}$ ): "type $\mathrm{C}$ ". Humid climate (rain is irregular intermediate conditions between w and $\mathrm{s}$ of Köppen classification). Specific range of temperature (warmer month over 22 degrees Celsius): "type a". According to the above, the continental territory of Uruguay falls into Köppen "Cfa" climate classification scheme.

Soils in this region are classified as superactive, thermic Pachic Argiudoll /Fine, smectitic, thermic Vertic Argiudoll (Durán et al. 2006) with Sandy Clay texture (41\% sand, 24\% lime, 35\% clay). The experimental field was cultivated under conventional tillage with vegetables for more than 40 years. Crop rotation from 2008 to 2011 consisted in sorgum in summer and oat and wheat in winter. Nitrogen and phosphorous fertilization was applied twice during maize growing season (only in the summer crop), with $150 \mathrm{~kg} \mathrm{~N} / \mathrm{ha} / \mathrm{yr}$ and $120 \mathrm{~kg} \mathrm{P} / \mathrm{ha} / \mathrm{yr}$. Site experiment plots were covered with herbaceous plants that are common in the region such as Convolvulus arvensis L.; Cynodon dactylon; and Digitaria sanguinalis and non-cultivated soil near the experimental site was covered mainly with $C$. dactylon. Soil chemical analyses were performed at a $0-15 \mathrm{~cm}$ soil depth at the beginning of the experiment (Table 1). 
Table 1. Agricultural and non- cultivated soil chemical properties (mean of the three samples)

\begin{tabular}{cccccccc}
\hline Soil type & $\mathbf{p H}$ & $\mathbf{O r g . C}$ & $\mathbf{N}$ & $\mathbf{N}-\mathbf{N O}_{\mathbf{3}}$ & $\mathbf{N}-\mathrm{NH}_{\mathbf{4}}$ & $\mathbf{P}(\mathbf{B r a y} \mathbf{I})$ & $\mathbf{C a}$ \\
\hline & $\left(\mathrm{H}_{2} \mathrm{O}\right)$ & $\%$ & $\%$ & $\mu \mathrm{g} \mathrm{N} / \mathrm{g}$ & $\mu \mathrm{g} \mathrm{N} / \mathrm{g}$ & $\mu \mathrm{g} \mathrm{P} / \mathrm{g}$ & $\mathrm{meq} / 100 \mathrm{~g}$ \\
\hline Agricultural soil & 7.1 & 2.57 & 0.21 & 6.7 & 15.6 & 67.5 & 17.7 \\
Non-cultivated soil & 6.3 & 4.55 & 0.36 & 3.7 & 28.1 & 8.4 & 17.9 \\
\hline Soil type & $\mathbf{M g}$ & $\mathbf{K}$ & $\mathbf{N a}$ & $\mathbf{T}$. Acidity & $\mathbf{C E C} \mathbf{p H} \mathbf{H}_{\mathbf{7}}$ & $\mathbf{T}$. Bases & Base Sat \\
\hline & $\mathrm{meq} / 100 \mathrm{~g}$ & $\mathrm{meq} / 100 \mathrm{~g}$ & $\mathrm{meq} / 100 \mathrm{~g}$ & $\mathrm{meq} / 100 \mathrm{~g}$ & $\mathrm{meq} / 100 \mathrm{~g}$ & $\mathrm{meq} / 100 \mathrm{~g}$ & $\mathbf{\%}$ \\
\hline Agricultural soil & 3.8 & 0.78 & 0.25 & 1.8 & 24.2 & 22.5 & 93 \\
Non-cultivated soil & 5.4 & 1.21 & 0.36 & 4.2 & 29 & 24.8 & 86 \\
\hline
\end{tabular}

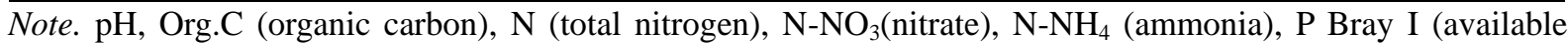
phosphorous), $\mathrm{Ca}, \mathrm{Mg}, \mathrm{K}, \mathrm{Na}, \mathrm{T}$. Acidity (titulable acidity), $\mathrm{CEC}_{\mathrm{pH}}$ (cation exchange capacity), T. Bases (total bases), Base Sat (base saturation percentage).

Two transgenic maize cultivars purchased from a commercial company (MONSANTO-DEKALB) were sown in January of 2012: DK 699 MGRR (resistant to lepidopteran insects and tolerant to glyphosate herbicide) and DK feed2 RR (tolerant to glyphosate). The experimental site was planted in plots of $5 \mathrm{~m} \times 5 \mathrm{~m}$ each, irrigated and treated with glyphosate. The cultivar DK 699 MGRR expresses the crylAb protein, from Bacillus thuringiensis ssp. kurstaki and provides resistance against larvae of the European corn borer (Ostrinia nubilalis). Both cultivars provide glyphosate herbicide tolerance by producing the enzyme CP4-4 (glyphosate tolerant 5-enolpyruvylshikimate-3-phosphate synthase- EPSPS from Agrobacterium tumefaciens).

\subsection{Sampling and Material Processing}

To address the effects of agricultural use and plant phenological stage on soil or rhizosphere bacterial communities, we collected three types of samples with three replications: agricultural soil from the experimental site, non-cultivated soil next to the site, and maize rhizosphere at elongation, flowering, and maturity. These samples and their IDs for both pyrosequencing and DGGE analyses are shown in Table 2.

Sampling of agricultural soil was performed before sowing at three plots randomly distributed within the experimental site. Within each plot, the analyzed sample consisted in the mixture of five samples taken in different points. Analyzed samples were treated as experimental replicates. Non- cultivated soil was sampled at three sites covered with natural vegetation adjacent to the experimental site; these samples were also treated as experimental replicates. Both types of soil samples (agricultural and non-cultivated soil) were collected with a soil-drill from the upper $10 \mathrm{~cm}$ soil layer. After that, root residues were removed by sieving ( $2 \mathrm{~mm}$ mesh size) and stored at $4^{\circ} \mathrm{C}$ for subsequent DNA extraction.

Rhizosphere samples of both cultivars were also collected in three maize plots randomly distributed within the experimental site, at the same phenological stage. In each plot, four plants at the same phenological stage were collected and mixed, in order to avoid individual plant variability, for each cultivar. The composed samples were treated as experimental replicates. Soil rhizosphere was processed following Baumgarte and Tebbe (2005) and stored at $-20^{\circ} \mathrm{C}$ until use for DNA extraction. Elongation phase was collected between V2 and V6 vegetative stages (when 2 to 6 leaves were visible), flowering stage was defined at R1 (reproductive stage), when any silk is visible, and maturity stage at R6 (physiological maturity) (Ritchie, 1992). 
Table 2. Identification of samples analyzed using both pyrosequencing (pyrosequencing ID), DGGE (DGGE ID) and sample characteristics (environment where they were collected, cultivar and phenological stage of maize)

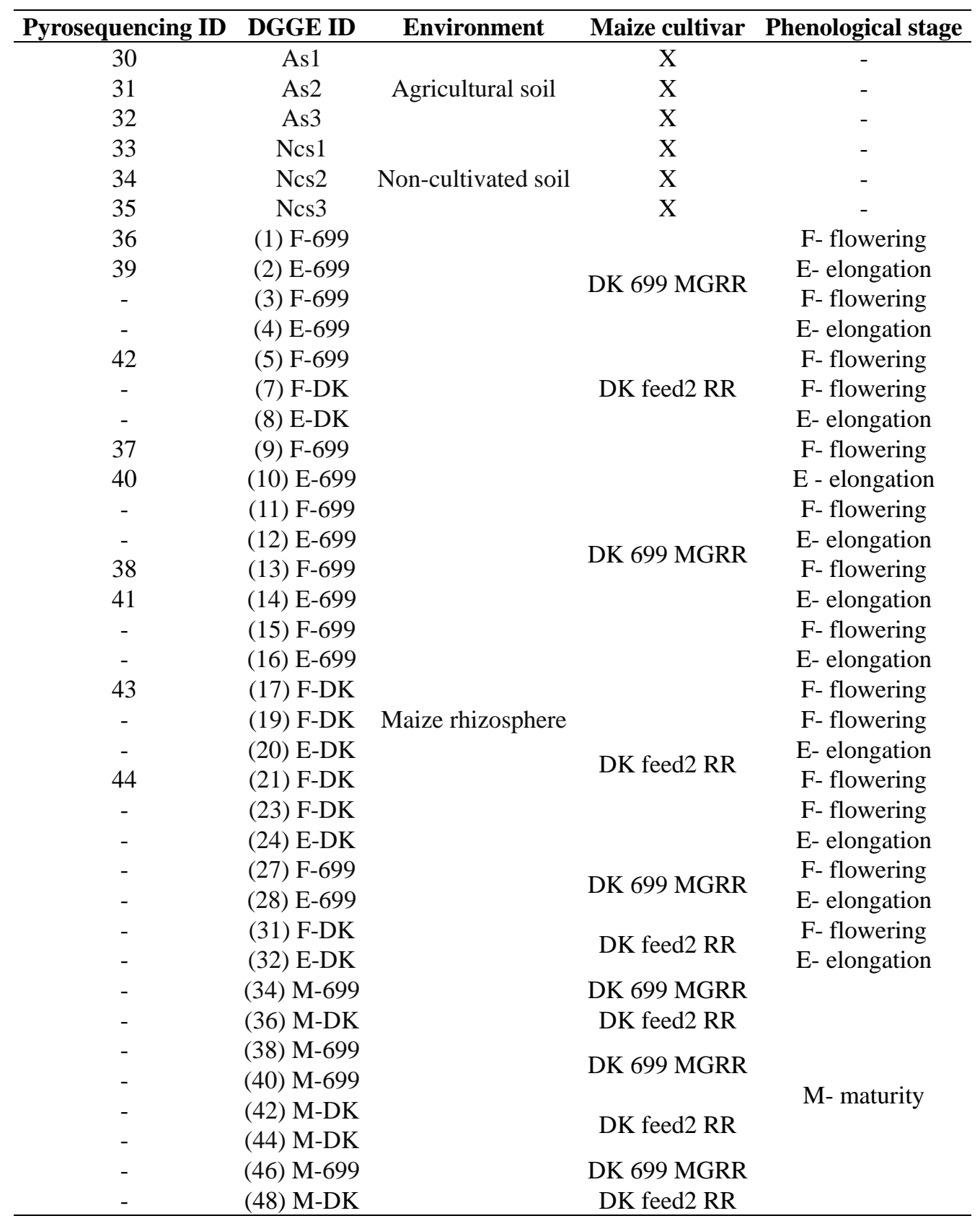

Note. DGGE ID identification refers to environment, maize cultivar and maize phenological phase. The absence of Pyrosequencing ID indicates that sample was not send for pyrosequencing.

Total genomic DNA was extracted from soil samples $(0,25 \mathrm{~g}$ fresh weight per sample) using "Power Soil DNA Isolation kit" (MOBIO Laboratories, Inc.) within two weeks from sample collection and processing. DNA quality (average molecular size and purity) and quantity were estimated by electrophoresis in $1 \%$ agarose gels and photometric measure. The sample identification code for DGGE analysis and pyrosequencing, as well as sample characteristics are detailed in Table A1. Only three replicate samples from rhizosphere of cultivars DK 699 MGRR and DK feed2 RR at elongation, flowering and maturity, as well as three replicate samples of both agricultural and non-cultivated bulk soil, were selected for pyrosequencing analysis.

\subsection{Denaturing Gradient Gel Electrophoresis (Dgge) Analysis}

Polymerase Chain Reaction of a 16S rRNA gene fragment was performed using the universal primers for 
bacterial domain F968-GC and R1378 (Heuer et al. 1997). PCR conditions were adjusted from those previously described (Peixoto et al. 2002). The PCR mix contained $2.5 \mathrm{U}$ of Taq polymerase, $1 \mathrm{X}$ reaction buffer, $2.5 \mathrm{mM}$ $\mathrm{MgCl}_{2}, 0.2 \mathrm{mM}$ of each dNTP, $0.1 \mathrm{mg} / \mathrm{mL} \mathrm{BSA}, 1 \%$ (vol/vol) formamide, $0.2 \mu \mathrm{M}$ of each primer, $1 \mu \mathrm{L}$ of an appropriate dilution of each DNA sample and necessary amount of ultrapure water for a final reaction volume of $50 \mu \mathrm{L}$. The PCR cycling program consisted on an initial denaturation step at $94^{\circ} \mathrm{C}$ for $2 \mathrm{~min}$, followed by 35 cycles of $94^{\circ} \mathrm{C}$ for $1 \mathrm{~min}, 55^{\circ} \mathrm{C}$ for $1 \mathrm{~min}$, and $72^{\circ} \mathrm{C}$ for $2 \mathrm{~min}$, and a final 10 -min extension at $72^{\circ} \mathrm{C}$. PCR products were first visualized by gel electrophoresis using $1 \%(\mathrm{wt} / \mathrm{vol})$ agarose gels with TAE buffer (Tris-acetate-EDTA) $1 \mathrm{X}$ at $100 \mathrm{~V}$ during $45 \mathrm{~min}$, and then using DGGE. DGGE was performed in a C.B.S. Scientific apparatus. PCR samples were loaded onto $6 \%(\mathrm{wt} / \mathrm{vol})$ polyacrylamide gels in $1 \mathrm{X}$ TAE buffer (Tris-acetate, EDTA; pH 7.5). The polyacrylamide gels were made with denaturing gradient ranging from 40 to $65 \%$ (where the $100 \%$ denaturant contained $7 \mathrm{M}$ urea and $40 \%$ formamide). The gels were run for $16 \mathrm{~h}$ at $70 \mathrm{~V}$ and $60^{\circ} \mathrm{C}$ (Peixoto et al. 2002), after which the gels were soaked for $1 \mathrm{~h}$ in SYBR Green and immediately photographed under UV light using a Multi-purpose image scanner Fuji Film Fla-9000 apparatus. Fingerprinting patterns were analyzed with Gelcompare II (Applied Maths, Ghent, Belgium), distance matrix was calculated with the Pearson correlation coefficient, and dendongrams were constructed with the UPGMA (unweighted pair group with mathematical averages) clustering algorithm.

\subsection{4- pyrosequencing of the $16 \mathrm{~S}$ rRNA Gene and Data Analysis}

Extracted DNA was precipitated with $95 \%$ ethanol and dried at $50^{\circ} \mathrm{C}$. The dehydrated samples were sent to the "Instituto de Agrobiotecnología" (INDEAR) in Rosario, Argentina, where the pyrosequencing analyses were performed using a 454/Roche GS FLX Titanium pyrosequencer.

Ten bp barcodes were used for sample identification. V4 region of the 16S rRNA gene was amplified using 563f (CACGACGTTGTAAAACGACAYTGGGYDTAAAGNG, in which the tag was included) and 802r (CAGGAAACAGCTATGACC) primers.

The sequences were analyzed using the Quantitative Insights Into Microbial Ecology (QIIME) software v1.6.0 (http://www.qiime.org/) (Caporasso et al. 2010). Reads having less than 200 bases, quality coefficient less than 25 , homopolymer runs higher than 6bp, and ambiguous bases, were removed. Operational taxonomic units (OTUs) were defined using the UCLUST algorithm (Edgar 2010) based on 97\% identity. Representative sequence for each OTU was picked following the most abundant method. Taxonomic classification of the representative sequence was performed through the bayesian Classifier RDP (Wang et al. 2007) using the Greengenes database (DeSantis et al. 2006) included in QIIME, with a confidence level of 50\%. The phylogenetic tree was constructed using the FastTree method (Price et al. 2009) from a multiple sequence alignment (MSA). The MSA was performed using QIIMEs PyNAST method (Caporasso et al. 2009) with default parameters. Alpha diversity was performed on the OTU table using the metrics observed_species, chao1, PD_whole_tree, dominance, equitability and rarefaction plots were constructed.

Matrices of Phylogenetic distances between OTUs were used as a mesure of beta diversity between microbial communities of studied samples using unweighted and weighted UniFrac distances. We performed a PCoA (Principal Coordinate Analysis) in order to examine differences on the total distribution of phyla and families within agricultural soil, non-cultivated soil, and rhizosphere related to either cultivar or maize phenological stage. Shannon's diversity index was calculated with an equal number of sequences per sample (3000). Statistical significance was determined using the Statistica 5.0 software (Statsoft) by ANOVA. The method used was the Tukey's HSD test $(p<0.05)$. The phylogenetic tree was constructed using the FastTree method (Price et al. 2009) from a multiple sequence alignment (MSA). The MSA was performed using QIIMEs PyNAST method (Caporasso et al. 2009) with default parameters. The diversity for each environment was also determined by Shannon index in i) rhizosphere from maize cultivar 699-MGRR at elongation and flowering; ii) rhizosphere from cultivars DK 699MGRR and DKfeed2 RR at flowering; and iii) Agricultural and non-cultivated soil (Table $3)$.

Relative abundance of the 10 most abundant bacterial phyla between the different comparisons was calculated by the sum of the absolute value of the reads of all OTUs belonging to each Phylum in each sample divided by the sum of the total of reads of that sample. Normal distribution of data was verified with Shapiro Wilk's test. Homogeneity of variances was assessed by Hartley's, Cochran's and Bartlett's tests. Values of abundance were compared by ANOVA and the Tukey's honestly significant difference HSD test (Honestly Significant Distance), (Table 4). The relative abundance of the 10 most represented phyla was analyzed using bar graphs comparing rhizosphere microbiomes of each cultivar at elongation and flowering phenological stages, rhizosphere microbiome of the same phenological stage in each cultivar, and also between agricultural and non-cultivated 
bulk soil. In this study we presented just the most informative comparisons graphs: i) microbiome of rhizosphere of maize cultivar DK 699-MGRR at elongation and flowering phenological phases (Figure 4); ii) microbiome of rhizosphere from flowering phases from both cultivars DK 699MGRR and DK feed2 RR (Figure 5); and iii) agricultural and non-cultivated bulk soil (Figure 6).

\section{Results}

\subsection{DGGE Data Analysis}
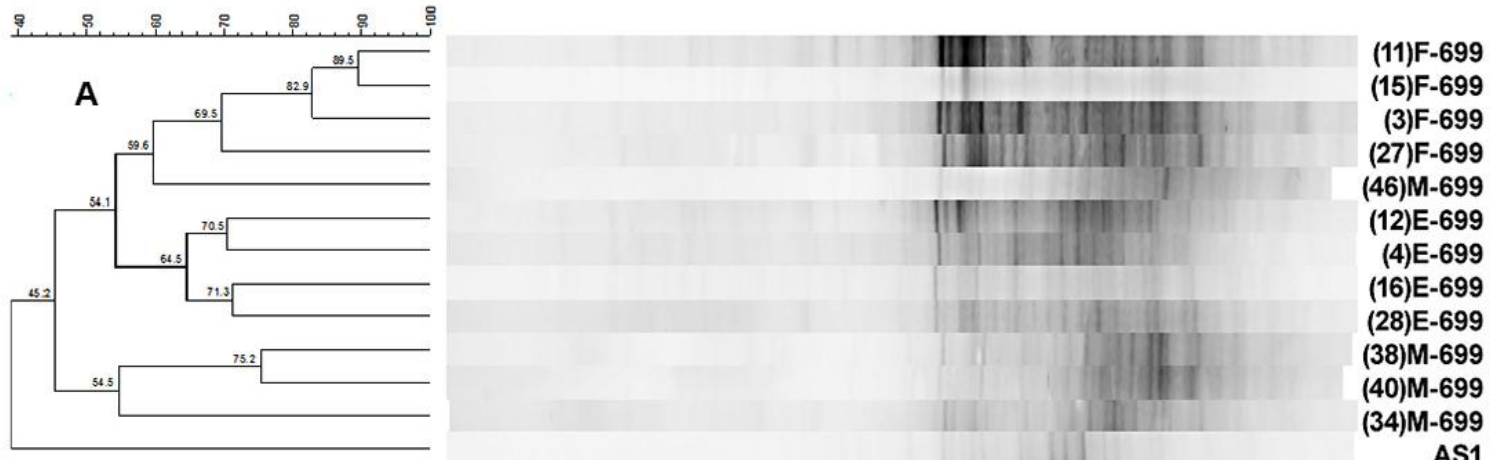

(11)F-699

(15)F-699

(27)F-699

(46)M-699

(12)E-699

E-699

(28)E-699

(38)M-699

(34)M-699

AS1

Figure 1. Cluster analyses and DGGE fingerprints of the bacterial community structure present in rhizosphere of maize DK-699 MGRR (A) at elongation (E), flowering (F) and maturity (M) phenological stages, and in agricultural bulk soil (AS1)

Note. Percentage of similarity among band patterns in samples is shown in the dendrograms. DGGE code number is shown in parentheses followed by phenological stage (F, E or M indicating flowering, elongation or mature stages), and 699 indicating cultivar DK-699 MGRR.
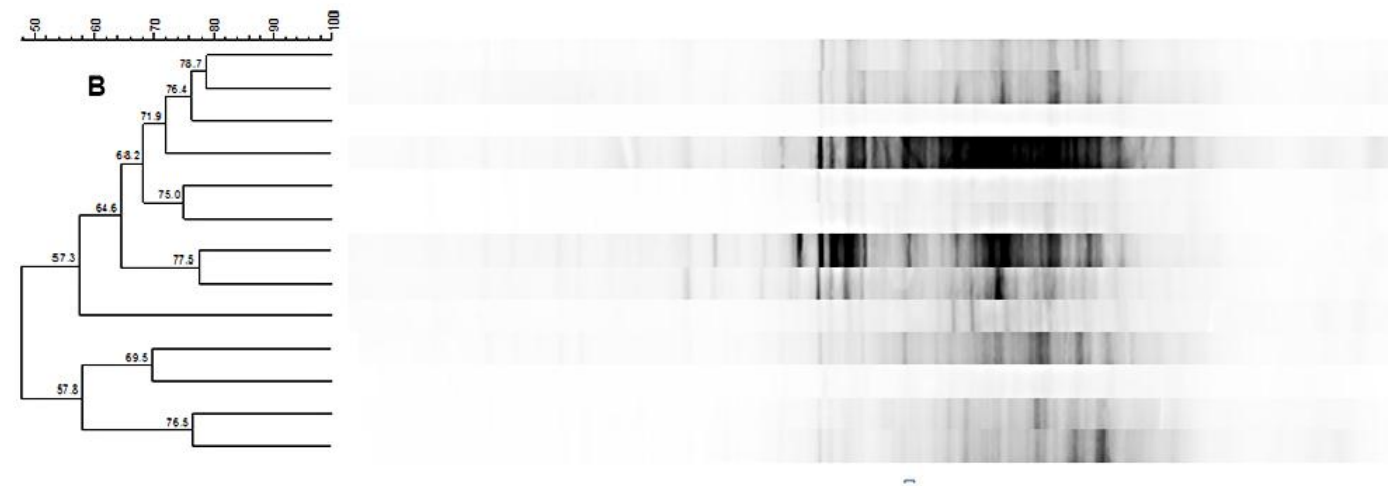

(23)F-DK (32)E-DK (19)F-DK (24)E-DK (20)E-DK (31)F-DK (7)F-DK (8)E-DK

AS2

(36)M-DK (48)M-DK (42)M-DK (44)M-DK

Figure 2. Cluster analyses and DGGE fingerprints of the bacterial community structure present in rhizosphere of maize DK feed2 RR (B) at elongation (E), flowering (F) and maturity (M) phenological stages, and in agricultural bulk soil (AS2)

Note. Percentage of similarity among band patterns in samples is shown in the dendrograms. DGGE code number is shown in parentheses followed by phenological stage (F, E or M indicating flowering, elongation or mature stages), and DK indicating cultivar DK feed2 RR.

For both cultivars, an evident separation between rhizospheric samples and control soil samples was observed (Figures 1 and 2). In DK699 MGRR cultivar, bacterial communities clustered separately at the different phenological stages, being mature stage more distant from both elongation and flowering stages $(45.2 \%$ of similarity, Figure 1) with the exception of just one sample (46). Bacterial communities of elongation and flowering phenological stages were more similar and clustered together at $54.1 \%$ of similarity. In the cultivar DK feed2 RR, bacterial communities from its elongation and flowering phenological stages clustered together with bulk soil control sample at $57.3 \%$ of similarity, being clearly different from bacterial communities at maturity (57.8\%, Figure 2).

By using DGGE, we found a clear separation among bacterial rhizosphere communities at elongation, flowering and maturity phenological stages of cultivar DK 699 MGRR, being both flowering and elongation rhizosphere 
communities more related between each other. However, cultivar DK feed2 RR samples at flowering and elongation clustered together but clearly separated from maturity phenological stage.

\subsection{4- pyrosequencing of $16 \mathrm{~S}$ rRNA Gene and Sequence Data Analysis}

Considering sequence similarity of $97 \%, 7,181$ OTUs were revealed. Of these, three remained unassignable ("Unassignable, Other"), two unclassified ("Unclassified, Other"), only one OTU was classified as an Archaea, phylum Euryarchaeota (genus Metalospirillum), and the rest were bacterial OTUs which were assigned to 38 phyla, 112 classes, 148 orders, 185 families and 239 genera differentially distributed among the samples analyzed. Among bacteria, 456 sequences $(0.8 \%)$ distributed in 227 OTUs could not be assigned to any phyla and belong to as yet uncultured/unrecognized bacteria. Rarefaction curves based on 97\% sequence similarity OTUs (observed_species, chao1 and PC-whole_tree) indicated that the communities were still not sampled to saturation at this respective taxonomic rank but followed similar progressions and revealed high diversity (supplementary material). That is an indication that the communities were of comparable diversity.

Environment- specific differences between the soil communities analyzed were evident in the principal coordinates analysis (PCoA) elaborated with the 16S rRNA gene amplicon data. Non-cultivated soil harbored bacterial communities that clustered apart from soil collected from both the agriculture experimental site and maize rhizosphere (in flowering and elongation phases). PCoA from weighted and unweighted Unifrac distances showed samples of rhizosphere at flowering phases clustering together, with just a few sample exceptions (Figure 3).

Table 4. Percentage of each taxonomic group was calculated as the mean of the percentage of the three replicates for the most represented taxonomic groups in Acidobacteria, Proteobacteria and Verrucomicrobia

\begin{tabular}{|c|c|c|c|c|c|}
\hline $\begin{array}{c}\text { Taxonomic groups } \\
\text { (identified class and family) }\end{array}$ & A. Soil & N-C Soil & $\begin{array}{c}\text { DK- } 699 \\
\text { MGRR- F }\end{array}$ & $\begin{array}{c}\text { DK- } 699 \\
\text { MGRR-E }\end{array}$ & $\begin{array}{c}\text { DK- feed2 } 2 \\
\text { RR- F }\end{array}$ \\
\hline Acidobacteria & $\%$ & $\%$ & $\%$ & $\%$ & $\%$ \\
\hline c__Chloracidobacteria; o__; f_ & 10.4 & 10.9 & $14 \bullet$ & 11.3 & 13.3 \\
\hline c__Acidobacteria-6; o__iii1-15; f__ & $8.5 \bullet$ & 7.8 & 7.3 & 8 & 7.4 \\
\hline $\begin{array}{c}\text { c__Solibacteres; o__Solibacterales; } \\
\text { f__Solibacteraceae }\end{array}$ & 2.7 & 3 & 2.8 & 2.5 & 2.4 \\
\hline Proteobacteria & $\%$ & $\%$ & $\%$ & $\%$ & $\%$ \\
\hline $\begin{array}{l}\text { c__Alphaproteobacteria; } \\
\text { o__Rhizobiales; } \\
\text { f__Bradyrhizobiaceae }\end{array}$ & $5 \bullet$ & $4,9 \bullet$ & 2.2 & 2.6 & 1.6 \\
\hline $\begin{array}{l}\text { c__Alphaproteobacteria; } \\
\text { o__Rhodospirillales; } \\
\text { f__Rhodospirillaceae }\end{array}$ & 2.6 & 1.4 & 2.2 & 2.6 & 1.6 \\
\hline $\begin{array}{c}\text { c__Deltaproteobacteria;o__Syntrop } \\
\text { hobacterales; } \\
\text { f__Syntrophobacteraceae }\end{array}$ & 1.1 & 0.9 & 2.2 & 1.9 & 2.7 \\
\hline Verrucomicrobia & $\%$ & $\%$ & $\%$ & $\%$ & $\%$ \\
\hline $\begin{array}{l}\text { c__[Spartobacteria];o__[Chthoniob } \\
\text { acterales];f_[Chthoniobacteraceae }]\end{array}$ & 7.2 & $12,8 \bullet$ & 6.9 & 6.1 & 4.4 \\
\hline $\begin{array}{c}\text { c__[Pedosphaerae }] ; 0 \_[\text {Pedosphaer } \\
\text { ales];f__ }\end{array}$ & 4.8 & 4.4 & 4.2 & 3.5 & 2.3 \\
\hline $\begin{array}{c}\text { c__[Pedosphaerae];o_[Pedosphaer } \\
\text { ales];f_Ellin517 }\end{array}$ & 2.6 & 1.8 & 2.6 & 2.1 & $7.5 \bullet$ \\
\hline
\end{tabular}




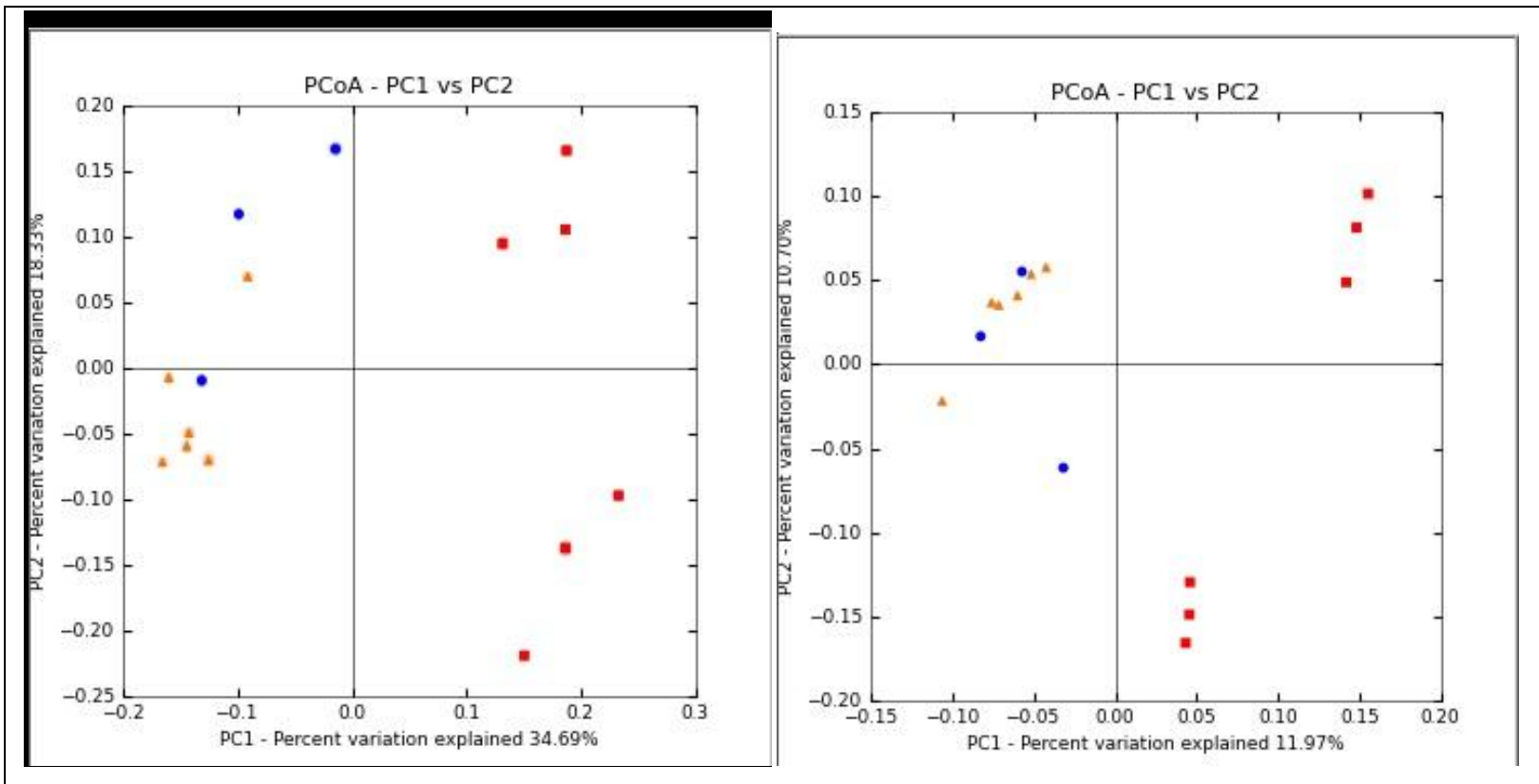

Figure 3. Principal coordinate analysis (PCoA) constructed with Quantitative Insights Into Microbial Ecology (QIIME) software (left: Weighted Unifrac distance, right: Unweighted Unifrac distance).

Note. Left: PC1 explained $34.69 \%$ of the variation while PC2 explained $18.33 \%$; Right: PC1 explained $11.97 \%$ of the variation while PC2 explained $10,70 \%$. Red squares represent samples from both agricultural and non-cultivated soil. Non- cultivated soil samples were in the upper left quadrant of weighted Unifrac PCoA and in the left- down quadrant of Unweighted Unifrac PCoA. Orange triangles refer to maize rhizosphere samples in flowering growing phase from both cultivars DK 699 MGRR and DK feed2 RR and blue circles represent maize rhizosphere samples in elongation phase of cultivar DK 699-MGRR.

Bacterial composition of the total of the samples sequenced revealed that the 10 most abundant phyla were Acidobacteria, Proteobacteria, Verrucomicrobia and, to a lesser extent, Gemmatimonadetes, Actinobacteria, Chloroflexi, Bacteroidetes, Planctomycetes, WS3 and Nitrospirae (Figures 4-6). Within rhizosphere environment, ANOVA revealed no differences among phenological stages for maize DK 699 MGRR, nor for the two cultivars at the same phenological stage (flowering). Furthermore, we found that non-cultivated soil evidenced a significant lower diversity $\left(\mathrm{H}^{\prime}=9.22\right)$ than agricultural soil $\left(\mathrm{H}^{\prime}=9.48\right)$ (Table 3$)$. Diversity also decreased in the rhizosphere of maize compared to agricultural soil. Also, Shannon index of non-cultivated soil has the same value of the index determined for rhizosphere of DK feed2 RR collected at flowering, which is the lowest of the rhizosphere samples. Rizosphere of variety DK 699 MGRR at elongation harbored a more diverse community than at flowering (Table 3).

Table 3. Shannon's diversity index calculated from pyrosequencing data with equal number of sequences per sample (3000)

\begin{tabular}{lcc}
\hline Environment & Shannon $\left(\boldsymbol{H}^{\prime}\right)$ & Significant differences \\
\hline Agricultural soil & 9.48 & $\mathrm{a}$ \\
Non-cultivated soil & 9.22 & $\mathrm{~b}$ \\
Rhizosphere of variety DK 699 MGRR collected at elongation & 9.40 & $\mathrm{ab}$ \\
Rhizosphere of variety DK 699 MGRR collected at flowering & 9.27 & $\mathrm{ab}$ \\
Rhizosphere of variety DK feed2 RR collected at flowering & 9.22 & $\mathrm{~b}$ \\
\hline
\end{tabular}

Note. Values are means of 3 replicates; different letters represent significant differences by ANOVA and Tukey's $\operatorname{HSD}(p<0.05)$.

No significant differences in relative abundance of analyzed bacterial phyla were found neither in cultivar DK 699-MGRR at elongation and flowering (Figure 4) nor between cultivars DK feed2 RR and DK 699-MGRR at flowering (Figure 5). Figure 6 shows the significant differences in relative abundances of several phyla between agricultural and non-cultivated soils: Bacteroidetes, Gemmatimonadetes, Planctomycetes, Proteobacteria and 
Verrucomicrobia. Among these phyla, Planctomycetes and Verrucomicrobia were more abundant in non-cultivated soil, while the others were more abundant in agricultural soil (Figure 6). Interestingly, we can observe that the relative abundance of the Gemmatimonadetes phylum almost doubled in rhizosphere samples compared to soil samples. Relative abundance increased from about $0.05 \%$ (Figure 6) to almost $0.1 \%$ (Figure 4 and 5). Other phyla did not show such a drastic change when comparing rhizosphere to bulk soil samples (Figures 4, 5 and 6).

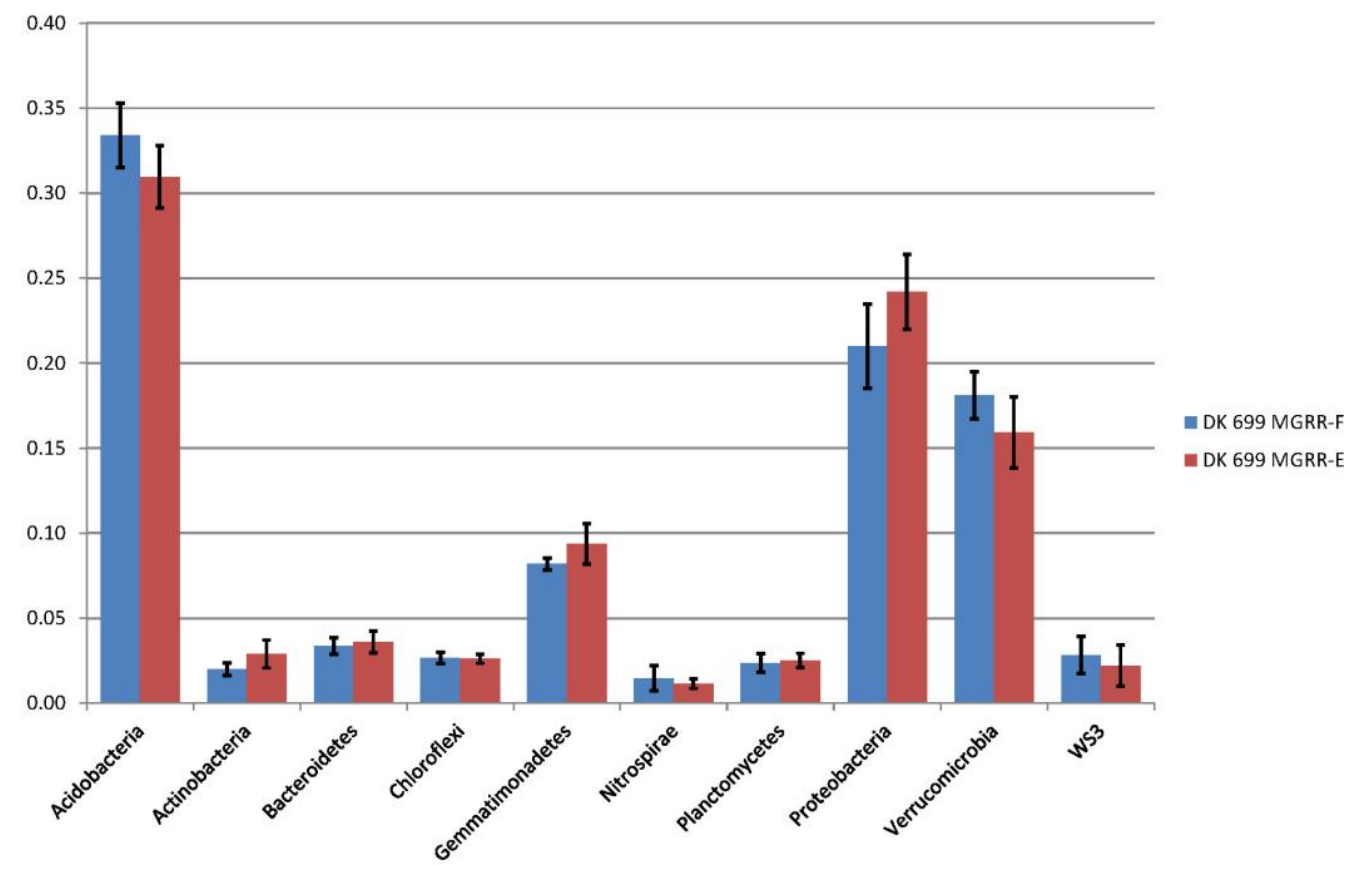

Figure 4. Relative abundance of the 10 most represented bacterial phyla in maize rhizosphere microbiomes of cultivar DK 699-MGRR at elongation (E) and flowering $(\mathrm{F})$ phases

Note. Statistical significance was tested with ANOVA and Tukey's $(p<0.05)$. Bars represent standard error.

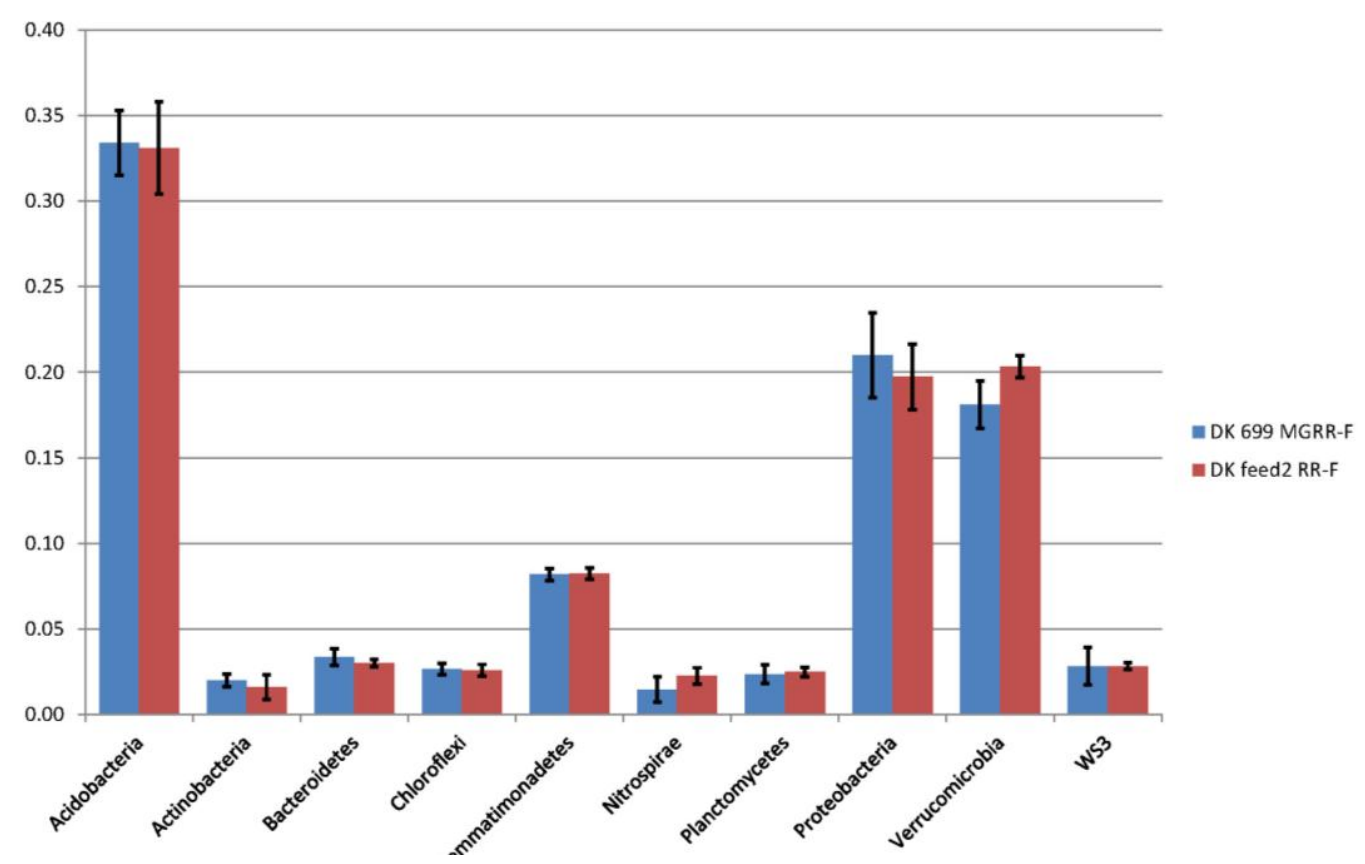

Figure 5. Relative abundance of the 10 most represented bacterial phyla in maize rhizosphere microbiomes of cultivar DK 699- MGRR and DK feed2 RR at flowering phase

Note. Statistical significance was tested with ANOVA and Tukey's ( $p \leqslant 0.05$ ). Bars represent standard error. 


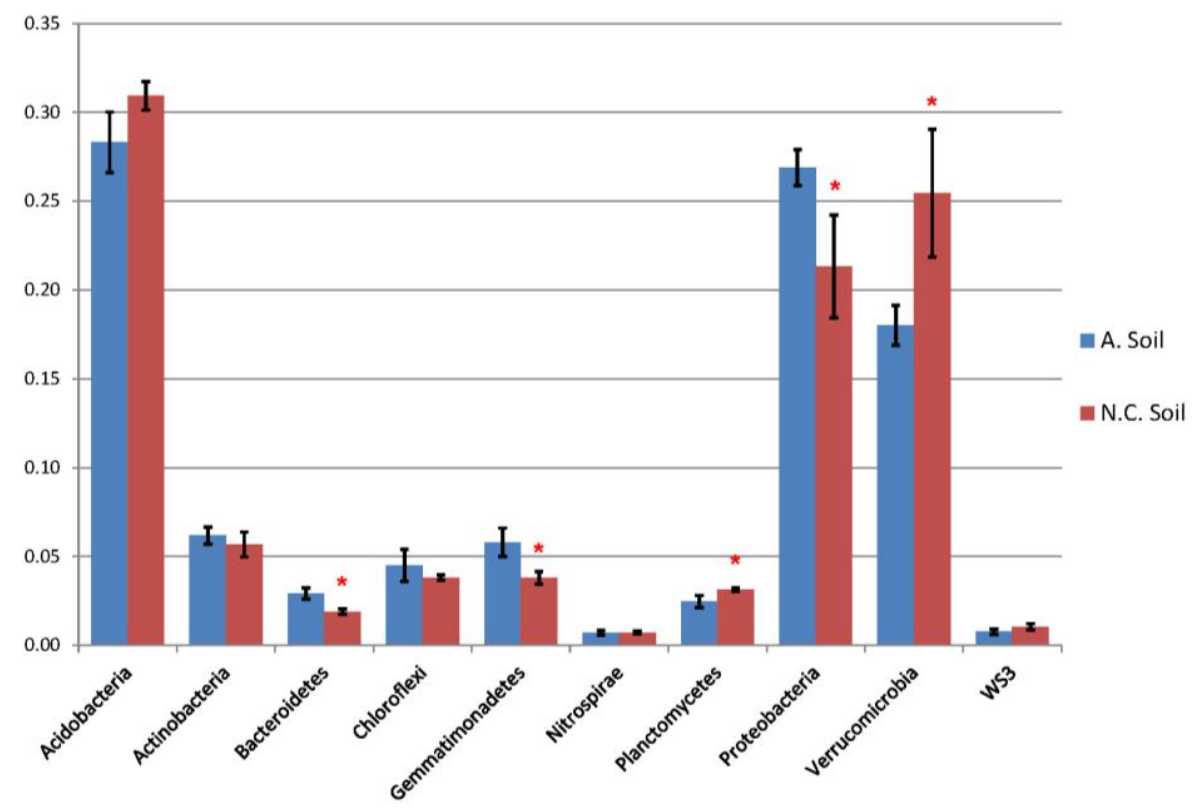

Figure 6. Relative abundance of the 10 most represented bacterial phyla in control samples of agricultural and non-cultivated soil collected within and nearby the experimental site

Note. Statistical significance was tested with ANOVA and Tukey's test $(p<0.05)$. Bars represent \pm standard error. (*): indicative of statistically significant difference.

Table 4. Percentage of each taxonomic group was calculated as the mean of the percentage of the three replicates for the most represented taxonomic groups in Acidobacteria, Proteobacteria and Verrucomicrobia.

\begin{tabular}{|c|c|c|c|c|c|}
\hline $\begin{array}{c}\text { Taxonomic groups } \\
\text { (identified class and family) }\end{array}$ & A. Soil & N-C Soil & $\begin{array}{c}\text { DK- } 699 \\
\text { MGRR- F }\end{array}$ & $\begin{array}{c}\text { DK- } 699 \\
\text { MGRR-E }\end{array}$ & $\begin{array}{c}\text { DK- feed2 } \\
\text { RR- F }\end{array}$ \\
\hline Acidobacteria & $\%$ & $\%$ & $\%$ & $\%$ & $\%$ \\
\hline c__Chloracidobacteria; o_; f__ & 10.4 & 10.9 & $14 \bullet$ & 11.3 & 13.3 \\
\hline c__Acidobacteria-6;o_iii $1-15 ; \mathrm{f}$ & $8.5 \bullet$ & 7.8 & 7.3 & 8 & 7.4 \\
\hline $\begin{array}{c}\text { c_Solibacteres; o_Solibacterales; } \\
\text { f__Solibacteraceae }\end{array}$ & 2.7 & 3 & 2.8 & 2.5 & 2,4 \\
\hline Proteobacteria & $\%$ & $\%$ & $\%$ & $\%$ & $\%$ \\
\hline $\begin{array}{l}\text { c__Alphaproteobacteria; } \\
\text { o__Rhizobiales; } \\
\text { f__Bradyrhizobiaceae }\end{array}$ & $5 \bullet$ & $4,9 \bullet$ & 2.2 & 2.6 & 1.6 \\
\hline $\begin{array}{l}\text { c__Alphaproteobacteria; } \\
\text { o__Rhodospirillales; } \\
\text { f_Rhodospirillaceae }\end{array}$ & 2.6 & 1.4 & 2.2 & 2.6 & 1.6 \\
\hline $\begin{array}{l}\text { c__Deltaproteobacteria;o_Syntropho } \\
\text { bacterales; f_Syntrophobacteraceae }\end{array}$ & 1.1 & 0.9 & 2.2 & 1.9 & 2.7 \\
\hline Verrucomicrobia & $\%$ & $\%$ & $\%$ & $\%$ & $\%$ \\
\hline $\begin{array}{c}\text { c__[Spartobacteria];o__[Chthoniobact } \\
\text { erales];f_[Chthoniobacteraceae] }\end{array}$ & 7.2 & $12,8 \bullet$ & 6.9 & 6.1 & 4.4 \\
\hline $\begin{array}{c}\text { c__Pedosphaerae }] ; 0 \_[\text {Pedosphaeral } \\
\text { es }] ; \mathrm{f} \_\end{array}$ & 4.8 & 4.4 & 4.2 & 3.5 & 2.3 \\
\hline $\begin{array}{c}\text { c__Pedosphaerae];o__[Pedosphaeral } \\
\text { es];f_Ellin517 }\end{array}$ & 2.6 & 1.8 & 2.6 & 2.1 & $7.5 \bullet$ \\
\hline
\end{tabular}

Note. $\mathrm{c}_{-}$: class; $\mathrm{o}_{-}$order; $\mathrm{f}_{-}$: family. Black circles indicate the highest percentages of relative abundance for some specific taxa within each environment.

Table 4 summarizes and compares the relative abundance of the most abundant taxonomic groups within Acidobacteria, Proteobacteria and Verrucomicrobia phyla, representative of each environment (agricultural, non- 
cultivated soil) and of the different rhizposhere samples. We observed that the class Chloracidobacteria (Acidobacteria) had the highest percentage of relative abundance in cultivar DK 699 MGRR at flowering, and the order "ii1-15" was higher in agricultural soil than in the other samples. The family Bradyrhizobiaceae (Proteobacteria) had a higher percentage of relative abundance in both agricultural and non-cultivated soil than in the other rhizosphere samples. We also found that the family Chthoniobacteraceae (Verrucomicrobia) was the most abundant taxa in non-cultivated soil, followed by "Ellin 517" (order Phedosphaerales), which predominated in rhizosphere of DK feed2 RR cultivar at flowering.

Through pyrosequencing technology, we identified OTU 1137 as the predominant one in agricultural soil samples. This OTU belongs to the genus Bradyrizobium of the phylum Proteobacteria. We also identified OTU 2337 (genus DA101, family Chthoniobacteraceae) of Verrucomicrobia and OTU 1449 (class Chloracidobacteria) of Acidobacteria as the predominant ones in non-cultivated soil. Among rhizospheric samples, other taxonomic groups were found to be more abundant; these included the genus Skermanella of Proteobacteria (OTU 3707); Opitutus gen. nov. of Verrucomicrobia (OTU 4202), the order N1423WL of Gemmatimonadetes (OTU 2126), and the family Nitrospirales of Nitrospira (OTU 6683).

\section{Discussion}

\subsection{Microbial Diversity in Maize Rhizosphere Samples, Agriculture and Non-Cultivated Bulk Soil Samples}

By using DGGE we found a clear separation among bacterial rhizosphere communities at elongation, flowering and maturity phenological stages of cultivar DK 699 MGRR, being both flowering and elongation rhizosphere communities more related between each other. However, cultivar DK feed2 RR samples at flowering and elongation clustered together but clearly separated from maturity phenological stage. By using 454-pyrosequencing (Figure 3) and DGGE (Figures 1,2) of the 16S rRNA gene, agricultural and non-cultivated soil grouped separately from rhizospheric soil.

PCoAs were constructed using 454- pyrosequencing data with both weighted and unweighted unifrac distances. In both PCoAs, rhizosphere samples at elongation and flowering phases of the two cultivars were clearly separated from soil samples. In PCoAs constructed using weighted unifrac distance we can observe that samples from the same cultivar at flowering (DK feed2 RR) grouped together (Figure 3- lowest samples at the left quadrant) suggesting a variety effect over the rhizosphere microbiome at flowering.

Additionally, through 454-pyrosequencing of the 16S rRNA gene we identified the most represented phyla as Acidobacteria, Proteobacteria and Verrucomicrobia, the same main phyla that Carbonetto et al. (2014) reported in Argentinean pampas. Similarly, Acidobacteria and Proteobacteria were the most abundant phyla reported by Fierer et al. (2007) in bulk soil across a wide range of ecosystems in North America.

Considering the 10 most abundant phyla for all samples, significant changes in the relative abundance of Bacteroidetes, Gemmatimonadetes, Planctomycetes, Proteobacteria and Verrucomicrobia were evidenced between agriculture and non-cultivated soil (Figure 6), whereas no differences were found between phenological stages or cultivars (Figures 4, 5). As reported by Fierer et al. (2007), within each targeted bacterial phyla there is an enormous amount of phylogenetic and physiological diversity and it is unlikely that an entire phylum would share common ecological characteristics. These authors suggested that the overall abundances of studied taxa or numerically abundant subgroups within these taxa can be broadly classified into copiotrophic or oligotrhophic categories. Copiotrophic attributes refer to microorganisms growing in fertilized soils with a high nutrient amendment, while an oligotrophic life style is more frequently found in microbiomes of non-cultivated homogenous soils (Carbonetto et al., 2014; Fierer et al., 2007). Fierer et al. (2007) found Acidobacteria was more abundant in soils with low availability of nutritional resources (oligotrophic strategists). Similarly, we found it was significantly more abundant in non-cultivated soil (considering $\mathrm{P} \leq 0,1$ ) than in agricultural soil (Figure 6). We also found that the phyla Planctomycetes and Verrucomicrobia were significantly more abundant in non-cultivated soil. Furthermore, we identify that the family Chthoniobacteraceae is the most abundant taxa within the phylum phyla Verrucomicrobia in this soil (Table 4). In non-cultivated soils, nutrients are present in more complex forms than in agricultural soils where fertilizers represent high inputs of rapidly available nutrients. On the other hand, according to Fierer et al. (2007), $\beta$ - Proteobacteria and Bacteroidetes would have copiotrophic attributes. In our study, these phyla plus the phylum Gemmatimonadetes were also significantly more represented in samples from agricultural soil (Figure 6). As shown in Table 4, the family Bradyrhizobiaceae (Proteobacteria) is more abundant in both agricultural and non-cultivated soil samples than in maize rhizospheric samples. Through pyrosequencing technology we identified the genus Bradyrhizobium as the most abundant taxa within soil samples. Like Rhizobium, this genus is composed by Gram negative nitrogen fixing species, but has a slower growing cycle. Probably, bacterial populations of Bradyrhizobium could have 
increased in agricultural soil because high nutritional resources and labile organic $\mathrm{C}$ pools were available due to its continuous agricultural use for 40 years. There, the high availability of $\mathrm{N}^{-\mathrm{NO}_{3}}$ and $\mathrm{P}$ (Table A2) would probably favor specific taxa with copiotrophic survival strategies. We also found that order "iiil-15" (Acidobacteria) was more abundant in agricultural and non- cultivated soils than in rhizospheric samples. Inversely, order Pedospheaerales (Verrucomicrobia) was much more abundant in non-cultivated soil than in both agricultural soil and rhizospheric samples (Table 4).

The highest Shannon diversity index values were those of agricultural soil $(\mathrm{H}=9.5)$, and the lowest ones those of non-cultivated soil $(H=9.2)$. The index value of non- cultivated soil is similar to the index of rhizosphere soil of DK feed2 RR at flowering, and did not significantly differ to the other rhizosphere samples index values (Table 3). This fact suggests that maize roots could have an influence on bacterial diversity similar to that of the roots of spontaneous plants in non-cultivated soil. Bacterial community structure in the rhizosphere is related to the production and diffusion of root exudates, which vary along the developmental stage of the plant, selectively favoring and revealing a specific bacterial composition for each phenological stage (Segheres et al. 2004; Cavaglieri et al. 2009; Gomes et al., 2001; Pereira et al. 2011, Brendensen et al. 2012). Our results showed a clear separation of elongation, flowering and maturity phenological stages in DGGE dendrogram of cultivar DK 699 MGRR (Figure 1). Among rhizospheric samples, the highest diversity index was found for the rhizosphere of cultivar DK 699 MGRR at elongation (H= 9.4), not significantly different from the same cultivar at flowering, but differing from cultivar DK feed2 RR at flowering (Table 3). Many studies based mainly in rhizospheric selected isolates also revealed a higher genetic diversity during the early stages of maize growth and suggested that the rhizosphere of young plants represents a more unstable ecosystem than the rhizosphere of mature plants does (Picard et al., 2000; Di Cello et al., 1997, Dalmastri et el., 1999; Seldin et al., 2000; Celius and Triplett, 2000). Gomes et al. (2001) also showed that the "rhizosphere effect" was much more pronounced for young roots compared to samples taken from mature maize plants using the TGGE technique (temperature gradient gel electrophoresis) for $\alpha$ and $\beta$ - proteobacteria, eubacteria and actinomycetes. In addition, Cavalieri et al. (2009) reported that plant development did not have influence on total cultivable microflora density, but it selectively influenced some bacterial and fungal rhizospheric groups. In our study we observed that the phylum Gemmatimonadetes (Zhang et al., 2003) increased in rhizospheric soil (Figures 4, 5) compared to bulk soil samples (Figure 6) while other phyla did not follow a similar pattern of enrichment in rhizosphere samples. Through pyrosequencing, we have also identified more abundance of the order Nitrospirales (phylum Nitrospirae), the genera Skermanella of $\alpha$-Proteobacteria (Lindsay 1999) and Opitutus gen. nov. (Verrucomicrobia) in all rhizosphere samples. The last mentioned phylum include a few culturable microorganisms that are sensitive to soil water availability (Chin et al., 2001). Among the members of this phylum, the family "Ellin517" was the most represented taxa in cultivar DK feed2 RR-F (Table 4).

Many studies of stability and diversity of microbial communities showed that the abundance of individual taxa changed according to different agricultural management practices (Acosta-Martinez et al., 2008; Yin et al., 2010, Figuerola et al. 2012; Carbonetto et al., 2014). Also using DGGE, Marileo et al. (2016) evaluated the total bacterial and ammonia-oxidizing bacteria communities shifts using various herbicides in urea-fertilized soils, revealing significant changes in community structures depending on the urea and herbicide dosage, herbicide type and sampling time. In our study, fertilization management in agricultural soil probably induced the development of copiotrophic bacterial groups leading to a higher bacterial diversity, as quantified by the Shannon index $(H=9,48)$. In agreement to these authors, we report significant changes in five of the ten more represented phyla between cultivated and non-cultivated soils. As previously mentioned, Planctomycetes and Verrucomicrobia were more represented in non-cultivated soils, while Bacteroidetes, Proteobacteria and Gemmatimonadetes prevailed in agricultural soil samples (Figure 6). Gemmatimonadetes were also more represented in rhizosphere samples compared to bulk soil samples (Figures 4, 5, 6). On the other hand, Ramirez- Villanueva et al. (2016) reported that conservation agriculture favored oligotrophic bacteria, e.g. Acidobacteria, Planctomycetes and Verrucomicrobia, while conventional agriculture favored bacteria that metabolize easily decomposable organic material, e.g. Actinobacteria (Powlson et al. 2012; Chavez- Romero 2016).

\subsection{Comparing Techniques}

Both pyrosequencing and DGGE techniques provide useful information in order to analyze shifts in diversity and structure of microbial communities; however, 454-pyrosequencing of the 16S rRNA gene would be a better choice when the objective is to identify specific microbial taxa. The currently-available massive parallel sequencing (using the 16S rRNA gene) of environmental DNA allows the rapid analysis of microbial communities at a much higher production rate than has previously been possible (Jones et al. 2009; Manter et al. 
2010). The "reads" provided by pyrosequencing have been shown to yield taxonomical information with considerable resolving power (Hus 2007; Liu 2008), thus allowing to establish the relative abundance of different members of the microbial communities under study. Quantitative measures like weighted unifrac are ideally suited to revealing community differences due to changes in relative taxon abundance; for example, when a particular set of taxa flourish because a limiting nutrient source becomes abundant, like in agricultural soil.

However, if carefully standardized to allow comparisons across multiple gels, DGGE still offers a relatively rapid, inexpensive and accurate alternative for large-scale comparative investigations (Ferrari et al., 1999; Forney et al., 2004; Alonso- Saez et al., 2007; Nakatsu et al., 2007; Sanchez et al., 2007). Through DGGE, we differentiated maize rhizosphere bacterial communities at culture developmental phases, being more evident in cultivar DK 699 MGRR. Using 454-pyrosequencing of 16S rRNA gene we also identified the 10 most represented phyla, which were the same in all samples tested, revealing only 5 phyla with significant differences in relative abundance between microbiomes of cultivated and non-cultivated soils.

\subsection{Perspectives}

The possible effects of genetic-engineered cultivars on soil and rhizospheric microbial communities have also been evaluated in many studies (Baumgarte and Tebbe 2005; Fang et al. 2005; Miethling-Graff et al. 2010; Barriuso et al. 2011; Dohrmann et al. 2012), among others. By DGGE, differences in rhizospheric eubacterial communities (both total and active) between Bt and non-Bt corn plants were detected (Castaldini et al. 2005). Despite the detection of the Cry $1 \mathrm{Ab}$ protein in the rhizosphere of maize, Baumgarte and Tebbe (2005) determined that the bacterial community structure was less affected by this protein than by other environmental factors, i.e. the age of the plants or field heterogeneities (during three sequential years of evaluation in two field sites in Germany). While we have concluded that soil bacterial communities are different among analyzed environments and among phenological stages of maize, further long-term experiments under a variety of conditions are required to validate taxonomic groups as potential indicators of agricultural management or determine the possible interaction of genetically-modified maize cultivars on soil or rhizospheric bacterial communities. However, we determined significant differences in soil microbiome revealing characteristic bacterial composition for cultivated, non-cultivated and rhizospheric soil samples using two culture- independent approaches, and discussed possible bacterial surviving strategies within a maize agro-ecosystem located in the South region of Uruguay. Moreover, we provided baseline information about environment-specific taxa, revealing some bacteria not yet identified in databases, which can be further explored.

\section{Acknowledgments}

We acknowledge Agr. Eng. Claudio García and his staff for implementing and maintaining the experimental maize growing site; as well as Agr. Eng. Stella Zerbino for suggestions about this experiment. We also thank B.S Nicolás Giannone and B.S. Pablo Fernández Garello for helping in soil and rhizosphere sampling; Dr. Mauricio Cantao, Alvaro Orradre and David Inderkum for their aid with the graphics, as well as Dra. Carolina Leoni for the critical review of the manuscript

\section{References}

Acosta- Martinez, V., Dowd, S., Sun, Y., \& Allen, V. (2008). Tag-encoded pyrosequencing analysis of bacterial diversity in a single soil type as affected by management and land use. Soil Biology and Biochemisty, 40, 2762- 2770. https://doi.org/10.1016/j.soilbio.2008.07.022

Alonso-Saez, L., Balague, V., Sà, EL, Sanchez, O., Gonzalez, J. M., Pinhassi, J., Massana, R., Pernthaler, J., Pedros- Alió, C., \& Gasol J. M. (2007). Seasonality in bacterial diversity in north- west Mediterranean coastal waters: assessment through clone libraries, fingerprinting and FIS. FEMS Microbiology Ecology, 60(1), 98-112. https://doi.org/10.1111/j.1574-6941.2006.00276.x

Baumgarte, S., \& Tebbe C. (2005). Field studies of the environmental fate of the Cry1 Ab Bt- toxin produced by transgenic maize (MON810) and its effect on bacterial communities in the maize rhizosphere. Molecular Ecology 14: 2539- 2551 https://doi.org/10.1111/j.1365-294X.2005.02592.x

Barriuso J., Marín, S., \& Mellado, R. P. (2011) Potential Accumulative Effect of the Herbicide Glyphosate on Glyphosate-Tolerant Maize Rhizobacterial Communities over a Three-Year Cultivation Period. PLos one Open Access. https://doi.org/10.1371/journal.pone.0027558

Berendsen, R. L., Pieterse C. M. J., \& Bakker, P. A. H. M. (2012). The rhizosphere microbiome and plant health. Trends in Plant Science, 17(8), 478-486 https://doi.org/10.1016/j.tplants.2012.04.001

Bidegain, M, Caffera, R. M. Características generales del clima sobre Uruguay. Meteorology Department. 
Faculty of Sciences UDELAR University of the Republic http://www.rau.edu.uy/uruguay/geografia/Uy_c-info.htm\#tiempo

Blackwood, C. B., \& Buyer, J. S. (2004). Soil microbial communities associated with Bt and Non-Bt corn in three soils. Journal of Environmental Quality, 33, 832- 836.

Blanco, C. A., Chiaravalle, W., Dalla-Rizza, M., Farias, J. R., García- Degano, M. F., ... Willink, E. (2016). Current situation of pests targeted by Bt crops in Latin America. Current Opinion in Insect Science, 15, $131-138$

Caporasso, J. G., Lauber, C. L., Walters, W. A., Berg-Lyons, D., Lozupone, C. A., Turnbaugh, P. J. et al. (2011). Global patterns of 16S rRNA diversity at a depth of millions of sequences per sample. Proceeding of National Academy of Sciences USA.108. 1, 4516-4522 https://doi.org/10.1016/j.cois.2016.04.012

Carbonetto, B., Rascovan, N., Alvarez, R., Mentaberry, A., \& Vazquez, M. P. (2014). Structure, Composition and Metagenomic Profile of Soil Microbiomes Associated to Agricultural Land Use and Tillage Systems in Argentine Pampas. PLoS One 9(6) https://doi.org/ 10.1371/journal.pone.0099949. eCollection 2014

Castaldini, M. A., Turrini, A., Sbrana, C., Benedetti, A., Marchionni, M., ... Giovannetti, M. (2005). Impact of Bt corn on rhizospheric and soil eubacterial communities and on beneficial mycorrhizal symbiosis in experimental microcosms. Applied and Environmental Microbiology, 71(11), 6719-6729 https://doi.org/10.1128/AEM.71.11.6719-6729.2005

Cavaglieri, L., Orlando J., \& Etcheverry, M. (2009). Rhizosphere microbial community structure at different maize plant growth stages and root locations Microbiological Research, 164, 391-399

Chelius, M. K., \& Triplett, E. W. (2000). Immunolocalization of dinitrogenase reductase produced by Klebsiella pneumoniae in association with Zea mays L. Applied Environmental Microbiology, 66, 783-787

Chin,_K. J., Liesack W., \& Janssen,_P. H. (2001). Opitutus terrae gen. nov., sp. nov., to accommodate novel strains of the division 'Verrucomicrobia' isolated from rice paddy soil. International Journal of Systematic and Evolutionary Microbiology, 51, 1965-1968

Cole, J. R., Wang, Q., Cardenas, E., Fish, J., Chai, B., ... Garrity, G. M. (2009). The Ribosomal Database Project: improved alignments and new tools for rRNA analysis. Nucleic Acids Research, 37, 141-145. https://doi.org 10.1093/nar/gkn879

Dalmastri, C., Chiarini, L., Cantale, C., Bevivino, A., \& Tabaccioni (1999). Soil type and maize cultivar affect the genetic diversity of maize root- associated Burkholderia cepacia populations. Microbial Ecology, 38, 273-284

Di Cello, F., Bevivino, A., Chiarini, L., Fani, R., Paffetti, D., Tabacchioni, S., \& Dalmastri, C. (1997). Biodiversity of a Burkholderia cepacia population isolated from the maize rhizosphere at different plant growth stages. Applied and Environmental Microbiology, 63, 4485-4493

DeSantis, P., Hugenholtz, N., Larsen, M., Rojas, E. L., Brodie, K., Keller, T., Huber, D., Dalevi, P., Hu, \& Andersen, G. L. (2006). Greengenes, a Chimera-Checked 16S rRNA Gene Database and Workbench Compatible with ARB T. Z. Applied and Environmental Microbiology, 72(7), 5069-5072 https://doi.org/10.1128/AEM.03006-05

Dohrmann, A. B., Küting, M., Jünemann, S., Jaenicke, S., Schlüter, A., \& Tebbe, C. C. (2012). Importance of rare taxa for bacterial diversity in the rhizosphere of Bt- and conventional maize varieties. The ISME Journal, 1-13. https://doi.org/10.1038/ismej.2012.77

Edgar R C (2010). Search and clustering orders of magnitude faster than BLAST. Bioinformatics 26: 2460-2461 https://doi.org/10.1093/bioinformatics/btq461

Durán, A., Califra, A., Molfino, J. H., Lynn, W. (2006). Keys to Soil Taxonomy for Uruguay. Washington: USDA. Natural Resources Conservation Service. 77p.

Figuerola, ELM, Guerrero, L. D., Rosa, S. M., Simonetti, L., Duval, M. E., Galantini, J. A., et al. (2012). Bacterial Indicator of Agricultural Management for Soil under No-Till Crop Production. PLoS ONE, 7(11), e51075. https://doi.org/10.1371/journal.pone.0051075

Egamberdieva, D., Kamilova, F., Validov, S. et al (2008) High incidence of plant growth stimulating bacteria associated with the rhizosphere of wheat grown on salinated soil in Uzbekistan. Environmental Microbiology, 10(1), 1-9 https://doi.org/10.1111/j.1462-2920.2007.01424.x. 
Engelhard, M., Hurek, T., \& Reinhold-Hurek, B. (2000). Preferential occurrence of diazotrophic endophytes, Azoarcus spp., in wild rice species and land races of Oryza sativa in comparison with modern races. Environmental Microbiology, 2, 131-141.

Fang, M., Kremer, R. J., Motavalli P. P., \& Davis, G. (2005). Bacterial Diversity in Rhizospheres of Nontransgenic and Transgenic Corn. Applied and Environmental Microbiology, 71(7), 4132-4136. https://doi.org/10.1128/AEM.71.7.4132-4136.2005

Ferrari, V. C., 7 Hollibaugh, J. T. (1999). Distribution of microbial assemblages in the Central Arctic Ocean Basin studied by PCR/DGGE: analysis of a large data set. Hydrobiologia, 401, 55-68. http://dx.doi.org/10.1023/A:1003773907789

Fierer, N., Bradford, M. A., \& Jackson, R. B. (2007). Toward an ecological classification of soil bacteria. Ecology 88(6), 1354-1364. https://doi.org/10.1890/05-1839

Forney, L. J., Zhou, X., \& Brown, C. J. (2004). Molecular microbial ecology: land of the one- eyed king. Current Opinion in Microbiology, 7, 210-220. https://doi.org/10.1016/j.mib.2004.04.015

Gomes, N. C. M., Heuer, H., Schönfeld, J., Costa, R., Mendonca-Hagler, L., \& Smalla, K. (2001). Bacterial diversity of the rhizosphere of maize (Zea mays) grown in tropical soil studied by temperature gradient gel electrophoresis. Plant and Soil, 232, 167. https://doi.org/10.1023/A:1010350406708

Gans, J., Wolinsky, M., \& Dunbar, J. (2005). Computation improvements reveal great bacterial diversity and high metal toxicity in soil. Science, 309, 1387-1390. https://doi.org/10.1126/science.1112665

Hart, M. M., Powell, J. R., Gulden, R. H., Dunfield, K. E., Pauls, K. P., Swanton, C. J, Klironomos, J. N., Antunes, P. M., Koch, A. M., \& Trevors, J. T. (2009). Separating the effect of crop from herbicide on soil microbial communities in glyphosate-resistant corn. Pedobiologia, 52, 253-262. https://doi.org/10.1016/j.pedobi.2008.10.005

Horwath, W. R., Elliot, L. F., \& Lynch, J. M. (1998). Influence of soil quality on the function of inhibitory rhizobacteria Letters in Applied Microbiology, 26, 87- 92

Hus, S., Huber, J., Morrison, H., Sogin, M. E., \& Welch, D. (2007). Accuracy and quality of massively parallel DNA pyrosequencing. Genome Biology, 8, 143. https://doi.org/10.1186/gb-2007-8-7-r143

Jones, R. T., Robenson, M. S., Lauber, C. L., Hamady, M., Knight, R., \& Fierer, N. (2009). A comprehensive survey of soil acidobacterial diversity using pyrosequencing and clone libraries ISME Journal, 3(4), 442-53 https://doi.org/10.1038/ismej.2008.127

Liu, Z., DeSantis, T., ANderson, G., \& Knight, R. (2008). Accurate taxonomy assignments from 16S sequences produced by highly parallel pyrosequencers. Nucleic Acids Research, 36(18), 120. https://doi.org/10.1093/nar/qkn491

Lozupone, C. A., Hamady, M., Kelley, S. T., \& Knight, R. (2007). Quantitative and qualitative beta diversity measures lead to different insights into factors that structure microbial communities. Applied Environmental Microbiology, 73, 1576-1585. https://doi.org/10.1128/AEM.01996-06

Mac. Arthur, R., \& Wilson, E. (1967). The theory of island biogeography. Princeton University Press, Princeton, New Jersey, USA.

Manter, D., Delgado, J., Holm, D., \& Stong, R. (2010). Pyrosequencing reveals a highly diverse and cultivarspecific bacterial endophyte community in potato roots. Microbial Ecology, 60(1), 157-166. https://doi.org/10.1007/s00248-010-9658-x

Mendes, R., Kruijt, M., de Bruijn, I., Dekkers, van der Voort, M, Schneider, J. H., ... Raaijmakers, J. M. (2011). Deciphering the rhizosphere microbiome for disease- suppressive bacteria. Science, 332, 1097-1100. https://doi.org/10.1126/science. 1203980

Miethling-Graff, R., Dockhorn, S., \& Tebbe, C.C. (2010). Release of the recombinant Cry3Bb1 protein of Bt maize MON88017 into field soil and detection of effects on the diversity of rhizosphere bacteria. European Journal of Soil Biology, 46, 41-48.

Nakatsu, C. H. (2007). Soil microbial community analysis using denaturing gradient gel electrophoresis. Soil Science Society of America Journal, 71, 562-571. https://doi.org/10.2136\%2fsssaj2006.0080

Oliver, J. D. (2010). Recent findings on the viable but non-culturable state in pathogenic bacteria, FEMS Microbiology Reviews, 34(4), 415-425 http://doi.org/101111/j.1574 69762009.00200 
Parisi, C., Tillie, P., \& Rodríguez-Cerezo, E. (2016). The global pipeline of GM crops out to 2020. Nature Biotechnology, 34, 31-36. http://doi.org/10.1038/nbt.3449

Powlson, D. S., Bhogal, A., Chambers, B. J., Coleman, K., Macdonald, A. J., Goulding, K. W. T., \& Whitmore, A. P. (2012). The potential to increase soil carbon stacks through reduced tillage or organic material additions in England and Wales: a case study. Agriculture Ecosystems \& Environment, 146, 23-33. https://doi.org/10.1016/j.agee.2011.10.004

Rascovan, N., Carbonetto, B., Revale, S., Reinert, M. D., Alvarez, R., ... Vazquez, M. P. (2013). The PAMPA datasets: a metagenomic survey of microbial communities in Argentinean pampean soils. Microbiome, 1(1), 21. http://doi.org/10.1186/2049-2618-1-21

Peixoto, R. S., Couthino da C., H. L., Rumjanek, N. G., Macrae, A., \& Rosado, A.S. (2002). Use of rpoB and 16S rRNA genes to analyze bacterial diversity of a tropical soil using PCR and DGGE. Letters in Applied Microbiology, 35, 316- 320

Picard, C., Di Cello, F., Ventura, M., Fani, R., \& Guckert, A. (2000). Frequency and biodiversity of 2,4-diacetylpholorglucinol- producing bacteria isolated from the maize rhizosphere at different stages of plant growth. Applied Environmental Microbiology, 66, 948-955

Ritchie, S. W., Benson, G., Lupkes, J. S., Herman, C. J., \& Hanway J. J. (1992). How a Corn Plant Develops Iowa State University of Science and Technology. Special Report No. 48

Romero, Y. C., Navarro- Noya, Y. E., Reynoso- Martínez, S. C., Sarria-Guzmán, Y., Govaerts, B., Verhulst, N., Dendooven, \& Luna, Guido-M (2016). 16S metagenomics reveals changes in the soil bacterial communitiy driven by soil organic C, N- fertilizer and tillage-crop residue management. Soil \& Tillage Research, 159, 1-8. http://doi.org/10.1016/j.still.2016.01.007

Sanchez, O., Gasol, J. M., Massana, R., Mas, J., \& Pedros-Alio, C. (2007). Comparison of different denaturing gradient gel electrophoresis primer sets for the study of marine bacteria plankton communities. Applied Environmental Microbiology, 73, 5962-5967. https://doi.org/10.1128/AEM.00817-07

Saxena, D., \& Stotzky, G. (2001). Bt corn has a higher lignin content or non-Bt corn. American Journal of Botany, 88(9), 1704-1706

Seghers, D., Wittebolle, L., Top, E. M., Verstraete, W., \& Siciliano, S. D. (2004). Impact of agricultural practices on the Zea mays L. endophytic community. Applied Environmental Microbiology, 70(3), 1475-82. https://doi.org/10.1128\%2FAEM.70.3.1475-1482.2004

Seldin, L., Rosado, A. S., Da Cruz, D. W., Nobrega, A., Van Elsas, J. D., \& Paiva, E. (1998). Comparison of Paenibacillus azotofixans strains isolated from rhizoplane, rhizospere and non-root- associated soil form maize planted in two different Brazilian soils. Applied Environmental Microbiology, 64, 3860-3868

Sessitsch, A., Reiter, B., \& Berg, G. (2004). Endophitic bacterial communities of field-grown potato plants and their plant- growth- promoting and antagonistic abilities Canadian Journal of Microbiology, 50(4), 239-249. https://doi.org/10.1139/w03-118

Smalla, K., Wieland, G., Buchner, A., Zock, A., Parzy, J., Kaiser, S., Roskot, N., Heuer, H., \& Berg, G. (2001). Bulk and Rhizosphere Soil Bacterial Communities Studied by Denaturing Gradient Gel Electrophoresis: Plant- Dependent Enrichment and Seasonal Shifts revealed. Applied and Environmental Microbiology, 67(10), 4742-4751. https://doi.org/10.1128/AEM.67.10.4742-4751.2001

Sul, W. J., Cole, J. R., Jesus, da C., E., Wang, Q., Farris, R. J., Fish, J. A., \& Tiedje, J. M. (2011). Bacterial community comparisons by taxonomy- supervised analysis independent of sequence alignment and clustering. PNAS, 108(35), 14637-14642. https://doi.org/10.1073/pnas.1111435108

Torsvik, V., Øvreås, L., \& Tringe, S. (2005).. Comparative metagenomics of microbial communities. Science, 308, 554-557. https://doi.org/10.1126/science.1107851

Wang, Q., Garrity, G. M., Tiedje, J. M., \& Cole, J. R. (2007). Naïve Bayesian Classifier for Rapid Assignment of rRNA. Sequences into the New Bacterial Taxonomy. Applied and Environmental Microbiology, 73(16), 5261- 5267. https://doi.org/10.1128/AEM.00062-07

Yin, C., Jones, K. L., Peterson, D. E., Garrett, K. A., Hulbert, S. H., \& Paulitz, T. C. (2010). Members of soil bacterial communities sensitive to tillage and crop rotation. Soil Biology \& Biochemistry, 42, 2111-2118. https://doi.org/10.1016/j.soilbio.2010.08.006

Zhang, H., Sekiguchi, Y., Satoshi, H., Hugenholtz, P., Hongik, K., Kamagata, Y., \& Nakamura, K. (2003). 
Gemmatimonas aurantiaca gen. nov., sp. nov., a Gram-negative, aerobic, polyphosphate accumulating micro-organism, the first cultured representative of the new bacterial phylum Gemmatimonadetes phyl. nov. International Journal of Systematic and Evolutionary Microbiology, 53, 1155-1163.

https://doi.org/10.1099/ijs.0.02520-0

Zhou, J., Xia, B., Huang, H., Treves, D. S., Hauser, L. J., Mural, R. J., Palumbo, A. V., \& Tiedje, J. M. (2003). Bacterial phylogenetic diversity and a novel candidate division of two humid region, sandy surface soils Soil Biology \& Biochemistry, 35(7), 915-924. https://doi.org/10.1016/S0038-0717(03)00124-X

\section{Copyrights}

Copyright for this article is retained by the author(s), with first publication rights granted to the journal.

This is an open-access article distributed under the terms and conditions of the Creative Commons Attribution license (http://creativecommons.org/licenses/by/3.0/). 